\title{
Fatores Determinantes da Oferta Turística do Município de Ilhéus (Bahia) na Alta Estação do Ano de 2007
}

\author{
Determinative factors of Offers Tourist of the City of Ilhéus (Bahia) in the High Station of \\ the Year of 2007
}

Cristiane Aparecida Cerqueira ${ }^{1}$

Carla Regina Ferreira Freire ${ }^{2}$

\begin{abstract}
Resumo
O presente trabalho tem por objetivo estimar os fatores determinantes da oferta turística do município de Ilhéus, na alta estação do ano de 2007. Fundamentado no conceito de que a oferta turística é subdividida em três categorias, atrativos, equipamentos/serviços, e infraestrutura, procurou-se avaliar estes componentes solicitando aos turistas notas que representassem seu nível de satisfação. Os dados foram analisados através da estatística descritiva e por meio da análise fatorial. Os resultados indicam que os atrativos naturais, a hospitalidade, a gastronomia e os meios de hospedagem agradaram. Por outro lado, o patrimônio histórico-cultural, as manifestações populares, as empresas de receptivo, os guias, e as diversões noturnas destacam-se como os mais criticados. Oito fatores foram extraídos, responsáveis por, aproximadamente, $60,4 \%$ da variância total dos dados.
\end{abstract}

Palavras-chave: satisfação; turistas; estatísticas; analise fatorial.

\begin{abstract}
The present work has for objective to esteem the determinative factors of offers tourist of the city of Ilhéus, in the high station of the year of 2007. Based on the concept of that it offers tourist is subdivided in three categories, attractive, equipment/services, and infrastructure, we wanted to evaluate these components requesting to the tourists grades that represented its level of satisfaction. The data had been analyzed through the descriptive statistics and the factorial analysis. The results indicate that natural attractive, the hospitality, the gastronomy and the ways of lodging had pleased. On the other hand, the historical-cultural patrimony, the popular manifestations, the companies of receptive, the guides, and the nocturnal diversions are distinguished as the most criticized. Eight factors had been extracted, responsible for, approximately, $60.4 \%$ of the total variance of the data.
\end{abstract}

Keywords: satisfaction; tourist; statistics; factorial analysis.

\footnotetext{
${ }^{1}$ Doutoranda em Economia (PIMES, Universidade Federal de Pernambuco); Mestre em Economia Aplicada (ESALQ - Universidade de São Paulo); Especialista em Economia Regional (Universidade Estadual de Santa Cruz); Professora Assistente do Departamento de Ciências Econômicas da Universidade Estadual de Santa Cruz. E-mail: cris_cerqueira@yahoo.com.br

${ }^{2}$ Mestre em Economia Aplicada (ESALQ - Universidade de São Paulo); Professora Assistente do Departamento de Ciências Econômicas da Universidade Estadual de Santa Cruz. E-mail: carlafreire@hotmail.com
} 


\section{Introdução}

No intuito de atrair um número cada vez maior de turistas e incentivar o crescimento do setor, a área do Estado da Bahia foi subdividida em dez zonas turísticas, cada uma denominada pelas características de sua identidade física e temática principal, a saber: Baía de Todos os Santos, Costa das Baleias, Costa do Dendê, Costa do Coqueiro, Costa do Descobrimento, Chapada Diamantina e Costa do Cacau, Sertão, Lagos do São Francisco e Caminhos do Oeste (SETUR, 2008).

Uma das zonas mais procuradas é a Costa do Cacau, conhecida pela cultura do cacau e pela produção de chocolate. Esta área é formada pelos municípios de Itacaré, Uruçuca, Una, Santa Luzia, Canavieiras e Ilhéus (SETUR, 2008). O turismo tem se constituído uma das alternativas à economia cacaueira que, nas duas últimas décadas, vem passando por grave crise levando a região a um estado de estagnação social e econômica, decorrente de uma conjunção de fatores estruturais que quebraram o ciclo produtivo da cultura base da economia local.

Como pioneiro na atividade turística, o município de Ilhéus é considerado um dos principais destinos da Costa do Cacau. Conhecido pelas paisagens naturais de ilhas fluviais e marítimas com muitos coqueirais, lagoas cercadas de vegetação nativa, rios e praias largas com areias claras, cuja faixa litorânea registra, aproximadamente, $93 \mathrm{~km}$. Como destaque, Ilhéus também possui um legado histórico datado da época de sua fundação, em 1534, que é divulgado em todo o mundo através das obras de Jorge Amado e Adonias Filho, atrativos que também são representados por meio do patrimônio histórico-cultural (SETUR, 2008).

Todavia, muitos outros municípios do Estado da Bahia e de outros estados brasileiros têm procurado investir na atividade do turismo, tornando-se, muitas vezes, concorrentes um dos outros. Ademais, a mobilidade social resulta em mudanças do perfil e das expectativas dos turistas. Tudo isto sinaliza a necessidade de aprimoramento dos destinos que perpassa pelo conhecimento da satisfação dos demandantes sobre o que está sendo ofertado. Ou seja, o destino precisa estar preparado para receber os não-residentes.

Sendo assim, este trabalho objetiva apresentar os fatores determinantes da oferta turística do município de Ilhéus, na alta estação do ano de 2007, procurando especificamente descrever a avaliação dos turistas sobre os atrativos, equipamentos, serviços e infra-estrutura local e 
estimar os componentes principais da oferta turística. Para tanto, este artigo está organizado da seguinte forma: na primeira seção, que é a introdução, após esta contextualização, apresenta-se a revisão de literatura e a metodologia; na segunda seção apresenta-se o desenvolvimento, que expõe os resultados referentes à análise descritiva e à estimativa dos fatores da oferta turística do destino; a terceira e última seção contém a conclusão.

\section{Revisão de Literatura}

\subsection{Oferta turística}

Para fundamentar os objetivos propostos, parte-se do entendimento de que o turismo é resultante de várias atividades econômicas, cuja oferta é definida como o conjunto de bens e serviços à disposição dos consumidores, os turistas, para a satisfação de suas necessidades. Por certo, os turistas, na função de consumidores, emitem juízos determinantes a respeito da qualidade dos bens e serviços que adquirem, pois quem deixa a sua residência espera encontrar o conforto contratado e pelo qual pagou (BENI, 2003; LAGE; MILONE, 2000).

A oferta turística é subdividida em três categorias: atrativos, equipamentos e serviços e infraestrutura. Considera-se atrativo turístico todo lugar, objeto ou acontecimento de interesse turístico que motiva o deslocamento de grupos humanos para conhecê-los. Esta categoria é composta pelos recursos turísticos primários, como os elementos hídricos (neve, gelo, águas minerais e termais) e a flora (florestas, bosques, matas e toda superfície natural). Também inclui os valores criados pela atividade do homem, tanto antigos como modernos (história, religião, cerimônia, tradições, folclore, cultura, monumentos históricos etc.) (Beni, 2003; Lage; Milone, 2000).

Equipamentos e serviços turísticos englobam o conjunto de edificações, instalações e serviços indispensáveis ao desenvolvimento da atividade turística. São constituídos pelos meios de hospedagem, alimentação, entretenimento, agenciamento, informações e outros serviços voltados para o atendimento aos turistas. Corresponde aos serviços produzidos, os quais, em conjunto com a oferta original, dão consistência ao consumo (Beni, 2003; Lage; Milone, 2000).

Já a infra-estrutura é formada pelo conjunto de obras e instalações de estrutura física de base, tais como o sistema de comunicações, transportes, serviços urbanos (água, esgoto, luz, 
sinalização, limpeza pública etc.). Os investimentos em infra-estrutura servem a todos os setores da economia e ao setor turístico por incidente. É o conjunto de obras e instalações da estrutura física de base, indispensáveis à qualidade de vida da população local e a todo empreendimento habitacional ou empresarial que venha a ser implantado (Beni, 2003; Lage; Milone, 2000).

Os indicadores da situação da oferta turística são: a existência ou não destes bens e serviços; o percentual de consumidores do turismo que os utilizam; o nível de atendimento; e o grau de satisfação dos turistas (Beni, 2003).

\subsection{Análise fatorial aplicada à avaliação da oferta turística}

A avaliação da oferta turística através de notas, atribuídas pelos turistas ou residentes, apresenta-se como um método eficiente conforme indicam as pesquisas realizadas por Schroeder (1996), Kozak e Rimmington (2000) e Andereck e Vogt (2000).

No estudo sobre a Dakota do Norte (Estados Unidos da América - EUA), Schroeder (1996) solicitou aos residentes a avaliação de vinte (20) atributos da oferta turística, segundo a Escala Likert, entre 1 (péssimo) e 7 (excelente). Utilizou-se a análise fatorial para identificar os componentes principais da imagem de Dakota do Norte como destino turístico, objetivando eliminar toda correlação entre os atributos. A rotação varimax selecionou quatro (04) fatores, responsáveis por $60,8 \%$ da variância dos dados, que descrevem essa imagem. O estudo sugere que a imagem dos residentes seja utilizada como auxílio no desenvolvimento de políticas de suporte para o incremento da atividade turística que ampliem a satisfação dos turistas e residentes com o destino (Schroeder, 1996).

Kozak e Rimmington (2000) procuram avaliar vários fatores da oferta turística além do nível de satisfação total do visitante de Mallorca (Espanha), durante o período de inverno. O estudo pretendeu identificar os elementos do destino que os turistas mais gostaram e os que eles não gostaram e determinar a contribuição de cada um destes itens na satisfação total. Os pesquisadores descrevem que as escalas tipo Likert podem ser empregadas com o propósito de avaliar experiências turísticas nas áreas de destino, porque elas efetivamente medem a satisfação dos consumidores e são de fácil construção e condução.

Assim, aplicaram um questionário composto de trinta e oito (38) questões baseadas numa grandeza de sete (07) pontos, para mensurar o nível de satisfação do turista, de acordo com a 
seguinte escala: não conhece (0), horrível (1), descontente (2), muito insatisfeito (3), pouco satisfeito ou não satisfeito (4), satisfeito (5), muito satisfeito (6) e encantado (7). Os trinta e oito (38) atributos mensurados foram resumidos através da análise fatorial, por meio do método dos componentes principais, via rotação varimax, responsáveis por $71,1 \%$ do total da variância dos dados, e quatro (04) fatores foram extraídos (Kozak; Rimmington, 2000).

Andereck e Vogt (2000) avaliaram a posição dos residentes sobre o turismo no Arizona através de quarenta e um (41) atributos da oferta turística utilizando cinco (05) pontos na escala, variando de extremamente divergente (1) a extremamente de acordo (5). Posteriormente, os 41 itens considerados foram reduzidos pela análise fatorial, via método dos componentes principais e rotação varimax, e quatro (04) fatores foram extraídos, responsáveis por $55,25 \%$ da variância dos dados.

\section{Metodologia}

\subsection{Métodos, técnicas e variáveis de pesquisa}

Para avaliar a oferta turística do município de Ilhéus, foi realizado levantamento de dados primários através da aplicação de questionários junto aos turistas presentes nas principais praias, na alta estação (janeiro) do ano de 2007. De cada família, apenas uma pessoa foi entrevistada, sendo excluídos os menores de idade. Dessa forma, foi possível obter informações de todos os tipos de turistas, desde os que se hospedam nos hotéis classificados pela Empresa Brasileira de Turismo (EMBRATUR), até aqueles que ficam hospedados nas casas de parentes e/ou amigos. Com relação à composição da amostra, não se sabia qual o número de turistas que iria visitar o município no período da pesquisa; em se tratando de uma população infinita, utilizou-se o critério de exaustão, que consiste na aplicação de um número máximo de questionários possíveis em um determinado período de tempo.

Foram abordados cento e oitenta e cinco (185) turistas, para coletar informações sobre o nível de satisfação quanto aos elementos da oferta turística. Semelhante à pesquisa realizada por Kozak e Rimmington (2000), os indicadores foram avaliados pelos turistas ao atribuir-lhes notas entre zero (0) e cinco (5). Esta escala do tipo Likert foi baseada nas seguintes escolhas: desconhecimento/não soube informar (0), péssimo (1), ruim (2), regular (3), bom (4) e ótimo (5). Dessa forma, foram analisados os vinte e sete (27) indicadores a seguir: 


\begin{tabular}{|l|l|l|}
\hline Os atrativos: & X15= táxi; \\
\hline $\mathrm{X} 1=$ atrativos naturais; & X16= sanitário das cabanas das praias; \\
\hline $\mathrm{X} 2=$ patrimônio histórico/cultural; & A infra-estrutura: \\
\hline $\mathrm{X} 3=$ manifestações populares; & $\mathrm{X} 17=$ meios de comunicação; \\
\hline Os equipamentos e serviços: & $\mathrm{X} 18=$ sinalização urbana; \\
\hline $\mathrm{X} 4=$ equipamentos de lazer; & $\mathrm{X} 19=$ segurança pública; \\
\hline $\mathrm{X} 5=$ passeios oferecidos; & $\mathrm{X} 20=$ limpeza pública; \\
\hline $\mathrm{X} 6=$ informações turísticas; & $\mathrm{X} 21=$ ônibus urbano; \\
\hline $\mathrm{X} 7=$ guias de turismo; & $\mathrm{X} 22=$ terminal marítimo; \\
\hline $\mathrm{X} 8=$ hospitalidade do povo; & $\mathrm{X} 23=$ terminal rodoviário; \\
\hline $\mathrm{X} 9=$ meios de hospedagem; & $\mathrm{X} 24=$ aeroporto; \\
\hline $\mathrm{X} 10=$ bares, restaurantes e cabanas; & & Das praias: \\
\hline $\mathrm{X} 11=$ comércio de artesanatos; & & $\mathrm{X} 25=$ qualidade ambiental das praias; \\
\hline $\mathrm{X} 12=$ diversões noturnas; & & $\mathrm{X} 26=$ limpeza das praias; \\
\hline $\mathrm{X} 13=$ empresas de receptivo; & & X27= segurança nas praias. \\
\hline $\mathrm{X} 14=$ sinalização turística; & & \\
\hline
\end{tabular}

\subsection{Análise estatística descritiva}

Para a análise das variáveis, foi utilizado o método estatístico descritivo. O método estatístico descritivo por meio do cálculo de média, proporção, moda etc. "compreende a organização, o resumo e a descrição dos dados [...] para que posteriormente, possam ser utilizados nas discussões de caráter descritivo ou analítico no relatório de pesquisa” (Lima, 2004, p. 73).

\subsection{Análise fatorial}

Por constituir uma atividade multidisciplinar, a compreensão do funcionamento do turismo, especificamente do que é ofertado, requer a análise de vários fatores (atrativos, equipamentos, serviços e infra-estrutura), o que dificulta a análise tabular, gráfica e mesmo estatística. Por isto, optou-se pelo uso adicional de técnicas de análise multivariada, como a fatorial, através do método de componentes principais, para redução e sumarização de dados (Schroeder, 1996; Kozak; Rimmington, 2000; Andereck; Vogt, 2000). 
A análise fatorial é uma técnica utilizada para redução e sumarização de dados, em pesquisas que trabalham com grande número de variáveis correlacionadas. A técnica identifica poucos fatores subjacentes que explicam as correlações entre um conjunto de variáveis. Também substitui o conjunto original de variáveis correlacionadas, por um conjunto novo e menor, de variáveis não-correlacionadas, para análise multivariada subseqüente, como a regressão múltipla (Sharma, 1996; Malhotra, 2001; Maroco, 2003).

\subsubsection{Considerações sobre o modelo de análise fatorial}

A análise fatorial é realizada em várias etapas. A primeira etapa determina a matriz das correlações entre as variáveis originais. Considerando $L$ observações para os $n$ indicadores, $X_{i j}($ com $i=1,2,3, \ldots, n$ e $\mathrm{j}=1,2,3, \ldots, L)$ a $j$-ésima observação do $i$-ésimo indicador e que a padronização dos indicadores é realizada, define-se a matriz de correlações simples entre os indicadores, dada por:

$\mathbf{R}=\mathbf{X} \mathbf{X}^{\prime}$,

$\mathrm{Na}$ segunda etapa, calculam-se os fatores necessários para representar as variáveis. Neste trabalho, os fatores foram extraídos pelo método dos componentes principais. $\mathrm{O}$ fator 1 representa a combinação linear que extrai a maior percentagem de variância dos indicadores. O fator 2 é a próxima combinação linear que maximiza o percentual da variância restante. Os demais fatores seguem o mesmo princípio. Ademais, os fatores extraídos são independentes entre si (são ortogonais).

$\mathrm{Na}$ análise fatorial, cada indicador $x_{i}$ representa uma combinação linear de $m$ fatores comuns e de um fator específico. Para o $i$-ésimo indicador, tem-se:

$$
\begin{aligned}
& x_{i j}=a_{i 1} f_{1 j}+a_{i 2} f_{2 j}+\ldots+a_{i m} f_{m j}+u_{i} y_{i j}, \text { ou } \\
& x_{i j}=\sum_{p=1}^{m} a_{i p f} f_{p j}+u_{i} y_{i j}
\end{aligned}
$$

em que $f_{p j}$ é o valor do $p$-ésimo fator comum para a $j$-ésima observação. Ou seja, é o valor dos fatores comuns desde que todos os indicadores sejam expressos em função deles; $a_{i p}$ é coeficiente; $u_{i}$ é coeficiente; $y_{i j}$ representa o $j$-ésimo valor do $i$-ésimo fator específico. $\mathrm{Ou}$ seja, é o valor único que representa a parte não explicada pelos fatores comuns. 
Representando o modelo de análise fatorial em notação matricial, tem-se:

$\mathbf{X}=\mathbf{A F}+\mathbf{U Y}$

em que:

A : matriz dos coeficientes dos fatores comuns;

F : matriz dos fatores comuns na qual cada linha corresponde a um fator;

$\mathbf{U}$ : matriz dos coeficientes dos fatores específicos; e

Y : matriz dos fatores específicos.

Admite-se que todos os fatores são ortogonais entre si e com vetores com módulo igual a 1; então, a partir dessas duas pressuposições, pode-se definir que:

$\mathbf{F F}^{\prime}=\mathbf{I} m$ (matriz unitária de ordem $\left.m\right)$

$\mathbf{Y} \mathbf{Y}^{\prime}=\mathbf{I} n$ (matriz unitária de ordem n)

Admite-se, também, que os $m$ fatores comuns são ortogonais com os $n$ fatores específicos, resultando numa matriz de zeros, assim:

$\mathbf{F Y} \mathbf{Y}^{\prime}=\mathbf{0}$.

Sabe-se que $\mathbf{R}=\mathbf{X X}^{\prime}$,

$\mathrm{Ou}$

$\mathbf{R}=\mathbf{X X}^{\prime}=\mathbf{A A}^{\prime}+\mathbf{U}^{2}$

De acordo com essa relação, para cada elemento da diagonal $\mathbf{R}$ (que é sempre 1), tem-se:

$1=\sum_{j=1}^{L} x_{i j}^{2}=\sum_{p=1}^{m} a_{i p}^{2}+u_{i}^{2}$

Os termos do último membro dessa expressão representam as proporções da variância de $x_{i}$, devido aos fatores comuns e aos fatores específicos, respectivamente.

A soma dos quadrados das variáveis de uma linha da matriz das cargas fatoriais denomina-se comunalidade. Esta corresponde à proporção da variância total de cada variável que é explicada pelo conjunto de fatores. Os valores da comunalidade estão num intervalo de 0 e 1 . 
Quanto mais próximo de 1, maior será a contribuição do fator para explicação de determinado indicador.

$\mathrm{Na}$ terceira etapa, os fatores extraídos são submetidos a uma rotação ortogonal, que consiste em transformar os fatores obtidos em novos fatores independentes. Com isso, espera-se que os indicadores que tenham correlação mais forte entre si estejam dentro de um mesmo fator, facilitando a interpretação dos mesmos. A rotação altera a parcela de contribuição de cada fator, mas mantém os valores das comunalidades e a proporção da variância explicada pelo conjunto de fatores. O critério utilizado de transformação ortogonal dos fatores foi o Varimax.

\subsubsection{Estatísticas associadas à análise fatorial}

$\mathrm{O}$ teste Kaiser-Meyer-Olkin Measure of Sampling Adequacy (KMO) permite verificar a consistência (adequação) dos dados originais à análise fatorial. É desejável que o valor do índice KMO seja acima de 0,6 e mais próximo de 1 (Sharma, 1996; Malhotra, 2001; Maroco, 2003; Paz et al., 2006):

O teste da esfericidade de Bartlett testa a hipótese nula de que as variáveis sejam nãocorrelacionadas na população. Isto é, testa a hipótese de que a matriz de correlação populacional é uma matriz identidade. Um valor elevado da estatística de teste favorece a rejeição da hipótese nula e estabelece a conveniência da análise fatorial.

O número de fatores é determinado com base em autovalores (eigenvalue), que representa a variância explicada por cada fator. São retidos apenas os fatores com autovalores (variâncias) superiores a 1. Ademais, determina-se o número de fatores com base na percentagem acumulada da variância extraída. Recomenda-se que os fatores extraídos respondam por, no mínimo, 60\% da variância (Sharma, 1996; Malhotra, 2001; Maroco, 2003).

Procede-se à rotação dos fatores, que facilita sua interpretação ao identificar as variáveis que apresentam grandes cargas sobre o mesmo fator. Neste trabalho, foram considerados os coeficientes de correlação entre cada fator e cada indicador, isto é, as cargas fatoriais acima de $0,50^{3}$. Por fim, o fator foi interpretado através das características das variáveis que o compõem.

\footnotetext{
${ }^{3}$ A decisão de estabelecer o valor, em módulo, de 0,50 da carga fatorial teve como referência os seguintes trabalhos: Sharma (1996), Maroco (2003) e Paz et al. (2006).
} 


\section{Análise Descritiva da Oferta Turística de Ilhéus Disponibilizada na Alta Estação}

Discutir a evolução da atividade turística do município de Ilhéus requer descrever a satisfação dos turistas não apenas com as condições dos atrativos, mas também exige o conhecimento da avaliação dos consumidores quanto aos equipamentos, serviços e infra-estrutura disponibilizada. Considerando a escala do tipo Likert entre 0 e 5, a Tabela 1 indica que os recursos naturais registraram a maior nota média $(4,29)$; do total, $44,3 \%$ dos turistas elegeram estes itens como ótimo e 44,3\%, como bom. Dessa forma, dos atrativos turísticos de Ilhéus, os recursos naturais (praias, mangues, matas, rios e lagoas, reservas de flora) são os mais satisfatórios. Certamente, a Mata Atlântica, as praias repletas de coqueirais e areia branca, as áreas de preservação ambiental etc. fazem de Ilhéus um destino convidativo para quem deseja contato com a natureza.

Os turistas foram interrogados sobre a qualidade ambiental das praias e, segundo a Tabela 1, a grande maioria respondeu que está satisfeita. De todos os abordados, 21,6\% e 51,4\% consideraram as praias em ótimo e bom estado de preservação e conservação, respectivamente; embora com nota média de 3,83, alguns entrevistados (20\%) fizeram questão de alertar que a qualidade ambiental das praias está regular. A limpeza das praias, mesmo considerada boa por $36,8 \%$ dos turistas, também requer atenção quando os resultados indicam percentuais significativos dos que avaliaram este item como regular $(32,4 \%)$, ruim $(9,7 \%)$ e péssimo $(9,2 \%)$.

Grande parte das praias, principalmente as da área sul, possui pequenas e médias cabanas que oferecem alimentos e bebidas, entretanto não há um planejamento quanto à localização destes equipamentos e à distribuição de suas redes de esgoto, comprometendo o aspecto visual e a preservação destas praias. Ademais, faz-se necessário investir em educação ambiental, que proprietários e funcionários das cabanas conscientizem-se e criem a estrutura necessária, como lixeiras e direcionamento adequado dos resíduos e dos esgotos, evitando o lixo e a contaminação destas áreas. Moradores e turistas também precisam colaborar neste sentido.

A segurança, em termos de viaturas, policiais e salva-vidas presentes nas praias, é desejada pelos turistas. Quando questionados quanto à qualidade destes equipamentos e serviços, $30,8 \%$ julgaram como bom. Por outro lado, os percentuais dos que ficaram insatisfeitos, $29,2 \%$ que registraram os serviços como regular, os que julgaram como ruim $(11,9 \%)$, 
péssimo $(10,3 \%)$ e a nota média $(2,69)$ indicaram que as praias necessitam de maior atenção do poder público (Tabela 1).

Tabela 1 - Avaliação da oferta turística presente no município de Ilhéus (Bahia), na alta estação do ano de 2007

\begin{tabular}{|l|l|l|l|l|l|l|l|}
\hline \multicolumn{1}{|c|}{$\begin{array}{c}\text { Oferta } \\
\text { turística/avaliação }\end{array}$} & $\begin{array}{c}\text { Ótimo } \\
(\%)\end{array}$ & $\begin{array}{c}\text { Bom } \\
(\%)\end{array}$ & $\begin{array}{c}\text { Regular } \\
(\%)\end{array}$ & $\begin{array}{c}\text { Ruim } \\
(\%)\end{array}$ & $\begin{array}{c}\text { Péssimo } \\
(\%)\end{array}$ & $\begin{array}{c}\text { Não } \\
\text { sabe } \\
(\%)\end{array}$ & $\begin{array}{c}\text { Nota } \\
\text { média }\end{array}$ \\
\hline Atrativos & & & & & & & \\
Atrativos naturais & 44,3 & 44,3 & 9,7 & 0,0 & 1,1 & 0,5 & 4,29 \\
Patrimon. hist./cultural & 17,8 & 39,5 & 11,4 & 5,9 & 2,2 & 23,2 & 2,95 \\
Manifestação popular & 5,9 & 21,1 & 17,8 & 2,7 & 4,9 & 47,6 & 1,78 \\
Equipamento/serviço & & & & & & & \\
Equipamentos de lazer & 4,3 & 26,5 & 19,5 & 7,0 & 6,5 & 36,2 & 2,06 \\
Passeios oferecidos & 7,6 & 24,3 & 11,4 & 6,5 & 7,0 & 43,2 & 1,89 \\
Informações turísticas & 8,1 & 23,8 & 16,2 & 8,6 & 11,9 & 31,4 & 2,14 \\
Guias de turismo & 5,4 & 13,0 & 11,4 & 6,5 & 10,8 & 53,0 & 1,37 \\
Hospitalidade do povo & 41,6 & 43,2 & 10,8 & 2,2 & 0,5 & 1,6 & 4,18 \\
Meios de hospedagem & 28,6 & 44,9 & 10,8 & 1,6 & 1,1 & 13,0 & 3,59 \\
Bar/restaur./cabanas & 26,5 & 49,2 & 17,3 & 2,7 & 0,5 & 3,8 & 3,87 \\
Comércio: artesanatos & 14,1 & 39,5 & 9,7 & 2,2 & 2,2 & 32,4 & 2,64 \\
Diversões noturnas & 4,9 & 16,8 & 14,6 & 5,9 & 12,4 & 45,4 & 1,59 \\
Empresas de receptivo & 2,7 & 18,9 & 1,4 & 3,2 & 2,7 & 61,1 & 1,32 \\
Sinalização turística & 4,9 & 25,9 & 28,6 & 11,4 & 13,0 & 16,2 & 2,50 \\
Táxi & 4,3 & 20,5 & 5,4 & 1,6 & 1,1 & 67,0 & 1,24 \\
Sanitários cabanas & 5,4 & 28,1 & 24,3 & 10,3 & 11,4 & 20,5 & 2,44 \\
Infra-estrutura & & & & & & & \\
Meios de comunicação & 14,1 & 51,9 & 13,5 & 3,2 & 2,2 & 15,1 & 3,27 \\
Sinalização urbana & 7,0 & 30,8 & 29,2 & 9,7 & 11,9 & 11,4 & 2,77 \\
Segurança pública & 3,2 & 24,3 & 29,2 & 6,5 & 13,5 & 23,2 & 2,28 \\
Limpeza pública & 2,7 & 25,9 & 25,4 & 13,0 & 23,2 & 9,7 & 2,43 \\
Ônibus urbano & 3,8 & 15,1 & 10,3 & 2,2 & 1,6 & 67,0 & 1,16 \\
Terminal marítimo & 1,1 & 4,9 & 5,4 & 3,8 & 1,6 & 83,2 & 0,50 \\
Terminal rodoviário & 1,6 & 12,4 & 11,4 & 3,2 & 2,7 & 68,6 & 1,01 \\
Aeroporto & 8,1 & 27,0 & 10,3 & 1,6 & 2,2 & 50,8 & 1,85 \\
Das praias & & & & & & & \\
Qualidade ambiental & 21,6 & 51,4 & 20,0 & 3,2 & 3,2 & 0,50 & 3,83 \\
Limpeza & 11,4 & 36,8 & 32,4 & 9,7 & 9,2 & 0,50 & 3,30 \\
Segurança & 4,9 & 30,8 & 29,2 & 11,9 & 10,3 & 13,0 & 2,69 \\
\hline
\end{tabular}

Fonte: Dados de pesquisa

Ainda avaliando os atrativos, de acordo com a Tabela 1, 39,5\% dos turistas consideraram o patrimônio histórico cultural do município de Ilhéus como bom. Entretanto, os demais alertaram para a necessidade de maior oferta destes recursos, dado que $17,8 \%$ dos abordados avaliaram como regular, a nota média foi de apenas 2,95 e $23,2 \%$ que não conseguiram julgar, 
muitas vezes pela indisponibilidade do atrativo, conforme salientam as pesquisas já realizadas. A história de Ilhéus remonta à época das capitanias hereditárias e também está atrelada à saga da lavoura cacaueira, bastante descrita por escritores reconhecidos mundialmente, como Jorge Amado. Dessa forma, museus, igrejas antigas, ruínas e outros monumentos históricos preservados e capazes de representar a cultura e a história local, além de atender as expectativas dos turistas, tornariam o destino Ilhéus mais diversificado e, portanto, mais atrativo.

Segundo os turistas, de todos os tipos de atrativos, a maior deficiência está nas manifestações populares do município de Ilhéus. A Tabela 1 revela que a maior parte dos entrevistados, $47,6 \%$, mostrou desconhecimento quanto às danças, cerimônias religiosas ou não, folclore do local, gastronomia típica, artesanatos, dentre outros manifestos. Do total, somente 21,1\% considerou estes componentes como bons, 17,14\% julgaram como regular, além da nota média, que foi de apenas 1,78. Geralmente no verão surgem algumas manifestações de capoeira, poucas demonstrações de artistas locais retratando o modo de viver dos moradores antigos e festividades como o carnaval, porém os dados revelam que os turistas consideraram estas atrações insuficientes.

Embora não promovam a motivação que leva ao deslocamento do turista, os equipamentos e serviços têm o papel de facilitar a estadia e também são observados e julgados. Com base na nota média, a hospitalidade, a gastronomia (bares, restaurantes e cabanas das praias) e a hospedagem foram os três (03) itens que mais agradaram os turistas presentes no município de Ilhéus, em janeiro de 2007.

A hospitalidade, ou seja, a forma de abordagem e receptividade dos moradores foi considerada ótima por $41,6 \%$ e boa por $43,2 \%$ dos abordados. Com nota média de 4,18 , poucos $(10,8 \%)$ foram os turistas que reclamaram achando regular a forma de aproximação dos habitantes. O povo baiano e o nordestino são geralmente reconhecidos como pessoas alegres e receptivas. Contudo, o improviso e a reduzida qualidade com preços justos incomodam os turistas (Tabela 1).

Os equipamentos e serviços gastronômicos registraram nota média de 3,87 e foram classificados como ótimos por $26,5 \%$ e bons por $49,2 \%$ dos entrevistados. Ilhéus possui opções de equipamentos de alimentos e bebidas quando agregam-se as cabanas de praia. 
Cabe, no entanto, estar atento aos percentuais dos que julgam regular (17,3\%), que podem estar desejando mais qualidade dos serviços e menor tempo para o atendimento. É preciso salientar que, embora quase um terço dos abordados tenha ficado satisfeito como os sanitários das cabanas de praia porque acharam bom $(28,1 \%)$, a nota média foi de apenas $2,44,24,3 \%$ julgaram como regular, 10,3\%, como ruim e 11,4\% consideraram péssimos, advertindo que é nestas cabanas que os turistas costumam passar a maior parte do seu tempo (Tabela 1).

Os meios de hospedagem também satisfizeram os turistas, pois, além da nota média de 3,59, $28,6 \%$ dos abordados consideraram estes equipamentos e serviços ótimos e 44,9\% classificaram como ótimos. Embora 10,8\% dos turistas proferiram que a hospedagem era regular, pode-se inferir que o município de Ilhéus oferece qualidade e diversidade de alojamento do tipo hotéis, pousadas e alguns resorts. As residências alugadas ou próprias e residências de parentes e amigos também são bastante procuradas, o que pode explicar o percentual dos que não quiseram avaliar (13\%) este componente da oferta.

Observando as notas médias da Tabela 1, os três (03) itens dos equipamentos e serviços que mais desagradaram os turistas presentes no município de Ilhéus, em janeiro de 2007, foram: as empresas de receptivo $(1,32)$, os guias de turismo $(1,37)$ e as diversões noturnas $(1,59)$.

Para os turistas, a situação dos serviços das empresas de receptivo dos guias de turismo do destino Ilhéus, em janeiro de 2007, encontra-se semelhante. Reduzidas proporções dos entrevistados avaliou como ótimo e bom, 11,4\% consideraram regular e a maioria não pôde emitir opinião, porque não utilizou ou não teve estes serviços à disposição. Na verdade, há uma necessidade de cursos para formação de guias. Também é preciso salientar que, além dos guias, faz-se necessária a formatação dos atrativos turísticos para que estes futuros colaboradores tenham o que apresentar aos turistas e satisfazê-los (Tabela 1).

Segundo a Tabela 1, o turista em Ilhéus clama por mais diversão noturna. Após aproveitar o sol e a praia, à noite, o turista não encontra o que fazer, porque são poucas as opções de entretenimento. Este é um dos itens mais criticados, dado que $45,4 \%$ não puderam julgar e os percentuais de regular $(14,6 \%)$ e péssimo $(12,4 \%)$ se destacam. Apenas $4,9 \%$ avaliaram como ótimos e $16,8 \%$, como bons.

Ademais, em janeiro de 2007, os equipamentos de lazer de Ilhéus registraram a nota média de 2,06 , agradaram somente $26,5 \%$ dos entrevistados, que classificaram este item como bom; 
19,5\% consideraram regulares e 36,2\% preferiram não avaliar. No centro da cidade, existem praças em condições de uso por turistas e moradores, mas boa parte, a exemplo da Praça do Cacau, não está em condições de ser utilizada. A Avenida Soares Lopes, localizada à beira mar, pela sua grande extensão poderia abrigar equipamentos de lazer e entretenimento, mas muitas vezes não possui a mínima condição de segurança, limpeza, iluminação para os que por lá circulam. O destino, então, precisa ampliar o número de clubes, estágios, ginásios, parques, balneários, mirantes, para aprimorar a oferta de lazer dos turistas.

Através da nota média, verifica-se que os equipamentos de lazer não se diferenciam significativamente da situação das informações turísticas, do comércio de artesanatos e dos passeios oferecidos. Grande parte dos turistas não soube avaliar estes itens da oferta; cerca de um quarto dos entrevistados classificaram como bom. O maior destaque é dado ao comércio de artesanatos, com nota média de 2,64 e 39,5\% de avaliação como bom (Tabela 1).

Organização e diversidade de atividades tornam-se necessárias porque, embora os turistas tenham gostado de curtir as amenidades ambientais do local, reclamaram da ausência do que fazer além de ir à praia. Com relação às informações, Ilhéus já possuiu alguns postos, localizados no centro da cidade, na orla sul, e tentou-se construir outro na BR 116, entre os municípios de Itabuna e Ilhéus, iniciativas consideradas insuficientes diante do número crescente de turistas que circulam no município e na região.

Desconsiderando os transportes (ônibus, terminal marítimo, terminal rodoviário, aeroporto e também os táxis, embora sejam serviços particulares), com relação à infra-estrutura, será destacado o item que mais agradou e que mais desagradou os turistas de Ilhéus, em janeiro de 2007. Os meios de comunicação (a disponibilidade de linhas de telefonia fixa e móvel, acesso a internet, correios etc.) obtiveram a maior nota média $(3,27)$ de toda a infra-estrutura, quando $51,9 \%$ dos turistas avaliaram como bons. Por outro lado, a segurança pública (disponibilidade de viaturas, policiais, delegacias) foi o item mais criticado, pois obteve nota média de 2,28, $29,2 \%$ de avaliação como regular, 13,5\% julgaram estes serviços péssimos e somente $24,3 \%$ consideraram bons.

Não há muita diferença entre as condições da limpeza pública, sinalização urbana e sinalização turística. A nota média foi registrada em torno de 2,5, e os percentuais atribuídos às condições de bom, regular e ruim denotam que o setor público precisa urgentemente 
ampliar sua atuação, seja através da limpeza do município, seja por meio das placas indicativas, principalmente porque (segundo pesquisas realizadas) muitos dos que vêm a Ilhéus se deslocam através de automóvel e necessitam de orientações para chegar e circular no destino (Tabela 1).

Pelo que indica a Tabela 1, solicitando a avaliação dos transportes, a maioria dos turistas revelou que não tinha condições de julgar esta infra-estrutura e os serviços de condução. Isto aconteceu ao questionar sobre o terminal marítimo $(83,2 \%)$, terminal rodoviário $(68,6 \%)$, ônibus urbano (67\%), aeroporto (50,8\%) e inclusive os táxis $(67 \%)$; por isso, as notas médias registradas foram pequenas. Conforme pesquisas realizadas, a maioria dos turistas vem de carro próprio, e utiliza este veículo para circular dentro do próprio município, não necessitando utilizar a infra-estrutura e os serviços particulares de transporte do município de Ilhéus.

\subsection{Componentes principais da oferta turística de Ilhéus da alta estação}

A análise fatorial foi realizada a partir das informações sobre os níveis de satisfação dos turistas quanto à oferta turística do município de Ilhéus, disponibilizada na alta estação do ano de 2007. Conforme pode ser visualizado na Tabela 2, o valor obtido para o teste $\operatorname{KMO}(0,771)$ indica que os dados originais são consistentes e permitem estabelecer a adequação da análise fatorial. O teste de esfericidade de Bartlett apresentou um valor elevado (1427,192), mostrando-se significativo a $1 \%(\mathrm{p}<0,001)$. Sendo assim, é improvável que a matriz de correlação seja uma identidade, ou seja, rejeita-se a hipótese nula do teste de que as variáveis não são correlacionadas. Dessa forma, os testes realizados permitem concluir que a amostra utilizada é apropriada ao emprego da análise fatorial.

A análise fatorial pelo método dos componentes principais e a rotação varimax foram utilizadas produzindo dimensões fatoriais ortogonais, com raízes características iguais ou maiores que um (1). 
Tabela 2 - Matriz rotacionada: cargas fatoriais e comunalidades dos 27 indicadores da oferta turística do município de Ilhéus (Bahia), da alta estação do ano de 2007

\begin{tabular}{|c|c|c|c|c|c|c|c|c|c|}
\hline \multirow{2}{*}{ Indicador } & \multicolumn{8}{|c|}{ Cargas fatoriais } & \multirow{2}{*}{$\mathrm{Com}^{4}$. } \\
\hline & $\mathrm{F}_{1}$ & $\mathrm{~F}_{2}$ & $\mathrm{~F}_{3}$ & $\mathrm{~F}_{4}$ & $\mathrm{~F}_{5}$ & $\mathrm{~F}_{6}$ & $\mathrm{~F}_{7}$ & $\mathrm{~F}_{8}$ & \\
\hline $\mathrm{X}_{1}$ & 0,286 & $-0,149$ & 0,071 & $-0,070$ & 0,459 & 0,249 & $-0,173$ & $-0,426$ & 0,598 \\
\hline $\mathrm{X}_{2}$ & 0,164 & 0,077 & 0,065 & 0,778 & 0,019 & 0,154 & 0,1590 & $-0,111$ & 0,704 \\
\hline $\mathrm{X}_{3}$ & 0,181 & 0,220 & 0,014 & 0,692 & $-0,029$ & $-0,004$ & ,028 & $-0,158$ & 0,587 \\
\hline $\mathrm{X}_{4}$ & 0,619 & 0,107 & 0,227 & 0,176 & 0,019 & 0,062 & $-0,010$ & $-0,061$ & 0,485 \\
\hline $\mathrm{X}_{5}$ & 0,726 & 0,203 & 0,065 & 0,231 & $-0,044$ & 0,062 & 0,008 & 0,042 & 0,634 \\
\hline $\mathrm{X}_{6}$ & 0,738 & 0,055 & 0,016 & $-0,024$ & 0,117 & 0,137 & 0,184 & 0,130 & 0,631 \\
\hline $\mathrm{X}_{7}$ & 0,793 & 0,075 & 0,026 & 0,076 & 0,008 & $-0,037$ & 0,123 & 0,108 & 0,669 \\
\hline $\mathrm{X}_{8}$ & $-0,056$ & $-0,123$ & 0,183 & 0,156 & 0,384 & 0,139 & $\mathbf{0 , 5 7 5 0}$ & 0,151 & 0,596 \\
\hline $\mathrm{X}_{9}$ & 0,286 & $-0,004$ & 0,028 & $-0,119$ & 0,011 & 0,124 & ,048 & 0,624 & 0,504 \\
\hline $\mathrm{X}_{10}$ & 0,242 & 0,005 & 0,015 & 0,111 & 0,104 & 0,447 & 0,350 & 0,274 & 0,479 \\
\hline $\mathrm{X}_{11}$ & 0,194 & 0,283 & 0,077 & 0,439 & 0,124 & $-0,205$ & 0,071 & 0,300 & 0,469 \\
\hline $\mathrm{X}_{12}$ & 0,085 & 0,163 & 0,246 & 0,629 & $-0,114$ & 0,078 & $-0,193$ & 0,219 & 0,595 \\
\hline $\mathrm{X}_{13}$ & 0,572 & 0,201 & 0,107 & 0,232 & 0,080 & $-0,239$ & $-0,177$ & 0,182 & 0,561 \\
\hline $\mathrm{X}_{14}$ & 0,261 & 0,024 & 0,656 & 0,031 & 0,017 & $-0,175$ & 0,176 & 0,088 & 0,569 \\
\hline $\mathrm{X}_{15}$ & $-0,027$ & 0,745 & 0,047 & 0,097 & 0,050 & 0,138 & 0,184 & $-0,095$ & 0,632 \\
\hline $\mathrm{X}_{16}$ & 0,045 & 0,139 & $-0,03$ & 0,124 & 0,148 & 0,681 & $-0,117$ & 0,217 & 0,585 \\
\hline$X_{17}$ & $-0,042$ & 0,152 & 0,198 & $-0,020$ & $-0,090$ & 0,677 & 0,117 & $-0,205$ & 0,586 \\
\hline $\mathrm{X}_{18}$ & $-0,131$ & 0,112 & 0,689 & 0,303 & 0,053 & 0,130 & $-0,018$ & 0,059 & 0,619 \\
\hline $\mathrm{X}_{19}$ & 0,025 & 0,245 & 0,694 & 0,091 & $-0,020$ & 0,260 & $-0,178$ & 0,012 & 0,651 \\
\hline $\mathrm{X}_{20}$ & 0,209 & $-0,241$ & 0,432 & 0,156 & 0,243 & 0,043 & 0,072 & 0,279 & 0,457 \\
\hline $\mathrm{X}_{21}$ & 0,142 & 0,773 & 0,104 & 0,190 & $-0,028$ & 0,086 & 0,102 & 0,099 & 0,693 \\
\hline $\mathrm{X}_{22}$ & 0,272 & 0,676 & 0,197 & 0,047 & $-0,080$ & 0,009 & $-0,250$ & 0,126 & 0,656 \\
\hline$X_{23}$ & 0,244 & 0,756 & 0,007 & 0,244 & 0,064 & 0,080 & $-0,035$ & $-0,050$ & 0,705 \\
\hline $\mathrm{X}_{24}$ & 0,379 & 0,305 & 0,023 & $-0,056$ & $-0,138$ & $-0,061$ & 0,638 & $-0,018$ & 0,670 \\
\hline $\mathrm{X}_{25}$ & $-0,024$ & 0,105 & 0,017 & $-0,048$ & $\mathbf{0 , 7 9 7}$ & 0,067 & 0,074 & $-0,081$ & 0,667 \\
\hline $\mathrm{X}_{26}$ & 0,068 & $-0,030$ & 0,151 & 0,007 & 0,836 & $-0,057$ & 0,023 & 0,127 & 0,748 \\
\hline $\mathrm{X}_{27}$ & 0,195 & 0,068 & 0,627 & $-0,117$ & 0,192 & $-0,012$ & 0,134 & $-0,223$ & 0,554 \\
\hline Eigenv. & 3,215 & 2,764 & 2,261 & 2,141 & 1,919 & 1,537 & 1,269 & 1,200 & \\
\hline $\begin{array}{c}\text { Variância } \\
(\%)\end{array}$ & 11,91 & 10,24 & 8,37 & 7,93 & 7,11 & 5,7 & 4,7 & 4,45 & \\
\hline
\end{tabular}

Nota: Teste Kaiser-Meyer-Olkin (KMO)=0,771; Teste de esfericidade de Bartlett $=1427,192$.

Fonte: Dados de Pesquisa

Pela Tabela 2, pode-se observar que a análise fatorial aplicada resultou na identificação de oito fatores com raiz característica maior que um (1), sendo que os fatores em conjunto explicam $60,4 \%$ da variância total das variáveis utilizadas. O método varimax possibilitou a obtenção de uma estrutura fatorial na qual uma e apenas uma das variáveis originais esteja

\footnotetext{
${ }^{4}$ Comunalidade.

${ }^{5}$ Eigenvalue.
} 
fortemente associada com um único fator, e pouco associada com os fatores restantes (MAROCO, 2003).

Na Tabela 2, estão apresentadas as cargas fatoriais, ou seja, os coeficientes de correlação entre os fatores e cada uma das 27 variáveis, e as comunalidades. Aceitam-se, como variáveis determinantes, aquelas que apresentam cargas fatoriais (component laodings) pelo menos superiores a 0,5 , em valor absoluto, expressão de forte associação entre o fator e o indicador. Para melhor interpretação da Tabela 2, estas cargas fatoriais são encontradas em negrito. Os valores estimados para as comunalidades, acima de 0,5 , que demonstram a capacidade explicativa conjunta dos oito fatores em relação a cada indicador, mostram que grande parte das variáveis tem a sua variabilidade significativamente captada e representada pelos fatores.

As variáveis $\mathrm{X}_{4}$ (equipamentos de lazer), apesar de apresentarem comunalidade inferior a $50 \%$, estão forte e positivamente associadas ao primeiro fator $\left(\mathrm{F}_{1}\right)$, resultado que vai de encontro às expectativas deste trabalho. As variáveis $\mathrm{X}_{10}$ (bares, restaurantes e cabanas), $\mathrm{X}_{11}$ (comércio de artesanatos) e $\mathrm{X}_{20}$ (limpeza pública) apresentam comunalidades inferiores de 0,5, mas registraram associações significativas de $0,447,0,439$, e 0,432 , respectivamente, com algum fator. Como são indicadores teoricamente importantes, decidiu-se por mantê-los no modelo fatorial.

A Tabela 2 e a Tabela 3 apresentam os oito fatores determinantes da oferta turística do município de Ilhéus, na alta estação do ano de 2007, segundo os turistas. Na Tabela 3, cada fator é nomeado de acordo com os respectivos indicadores que o compõem. O primeiro fator $\left(\mathrm{F}_{1}\right)$ encontra-se correlacionado com os indicadores equipamentos de lazer $\left(\mathrm{X}_{4}\right)$, passeios oferecidos $\left(\mathrm{X}_{5}\right)$, informações turísticas $\left(\mathrm{X}_{6}\right)$, guias de turismo $\left(\mathrm{X}_{7}\right)$ e empresas de receptivo $\left(\mathrm{X}_{13}\right)$. Dessa forma, $\mathrm{F}_{1}$ representa a "Capacidade de apresentar e acompanhar o turista ao entretenimento". Como visto na análise descritiva, o destino Ilhéus precisa ampliar todos estes equipamentos e serviços porque os turistas não ficaram satisfeitos com o que foi ofertado na alta estação do ano de 2007. 
Tabela 3 - Fatores determinantes da oferta turística do município de Ilhéus (Bahia), na alta estação do ano de 2007

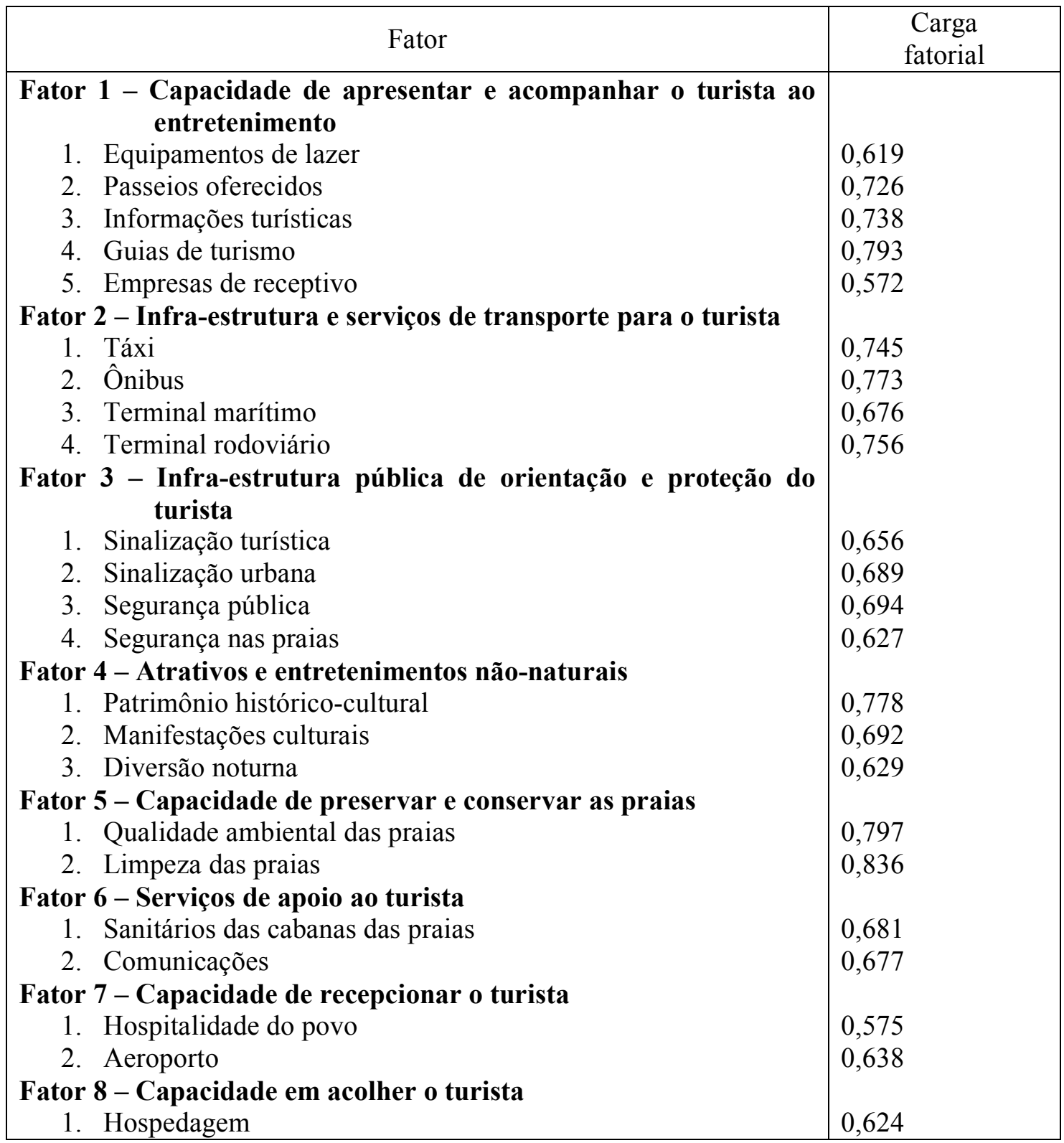

$\mathrm{Na}$ verdade, há muito para ser feito neste sentido, pois o município de Ilhéus necessita aperfeiçoar seus produtos, principalmente no que diz respeito à oferta de entretenimento e na seqüência investir numa central de atendimento que funcione em conjunto com todo o sistema turístico. O turista, quando chega a um lugar desconhecido, precisa de várias orientações 
sobre hospedagem, serviços gastronômicos e de diversões, dentre outros, que podem ampliar sua capacidade de aproveitamento e satisfação com a estadia.

O segundo fator $\left(\mathrm{F}_{2}\right)$ engloba os indicadores táxi $\left(\mathrm{X}_{15}\right)$, ônibus $\left(\mathrm{X}_{21}\right)$, terminal marítimo $\left(\mathrm{X}_{22}\right)$ e terminal rodoviário $\left(\mathrm{X}_{23}\right)$. Por isto, $\mathrm{F}_{2}$ indica a "infra-estrutura e serviços de transporte para o turista" (Tabela 3). Em Ilhéus, estes componentes da oferta não são utilizados pela maioria dos turistas que se deslocam até o município de carro próprio e circulam com este mesmo veículo, segundo pesquisas realizadas anteriormente e conforme descrito na análise descritiva.

Conforme a Tabela 3, o terceiro fator $\left(\mathrm{F}_{3}\right)$, designado como a "Infra-estrutura pública de orientação e proteção do turista”, engloba os indicadores sinalização turística $\left(\mathrm{X}_{14}\right)$, sinalização urbana $\left(\mathrm{X}_{18}\right)$, segurança pública $\left(\mathrm{X}_{19}\right)$ e seguranças nas praias $\left(\mathrm{X}_{27}\right)$. Qualquer que seja a motivação, turismo de sol e praia, turismo de lazer, ecoturismo, turismo cultural, turismo de negócios ou qualquer outra, o Fator 3 evidencia que as pessoas necessitam do apoio do poder público em termos de infra-estrutura e serviços que facilitem sua estadia, de forma que consigam se deslocar mas tenham suas vidas resguardadas.

$\mathrm{O}$ quarto fator $\left(\mathrm{F}_{4}\right)$ envolve os indicadores patrimônio histórico-cultural $\left(\mathrm{X}_{2}\right)$, manifestações populares $\left(\mathrm{X}_{3}\right)$,) e diversão noturna $\left(\mathrm{X}_{12}\right)$, sendo, portanto, classificado como "Atrativos entretenimento e não-naturais" (Tabela 3). Este fator destaca as expectativas dos turistas do município de Ilhéus, cuja história é registrada e reconhecida na literatura internacional, que acende o desejo de se conhecer os legados dos antepassados, quer seja no aspecto material ou imaterial. Ademais, outro grande anseio dos turistas é ter a disposição variedades de distrações noturnas, como boates, cinemas, teatro, por exemplo.

A Tabela 3 apresenta o Fator $5\left(\mathrm{~F}_{5}\right)$, rotulado de "Capacidade de preservar e conservar as praias" e que engloba os indicadores qualidade ambiental das praias $\left(\mathrm{X}_{25}\right)$ e limpeza das praias $\left(\mathrm{X}_{26}\right)$. As informações da análise fatorial vêm corroborar com o fato de que Ilhéus muito atrai pelas amenidades ambientais, mas que os turistas atrelam a sua satisfação ao nível de cuidado no uso destes recursos.

O sexto fator (F6), que agregou os indicadores sanitários das cabanas das praias (X16) e os meios de comunicação (X22), é denominado "Serviços de apoio ao turista". O Fator 6 comprova como a análise da atividade turística é complexa porque o turista não exige um produto único mas uma série de bens e serviços. Não basta que o destino oferte atrativos 
exuberantes, pois o turista também quer qualidade até mesmo em serviços que para alguns são meros detalhes, como a limpeza dos banheiros e a facilidade em se comunicar.

Observando a Tabela 3, verifica-se que o sétimo fator $\left(\mathrm{F}_{7}\right)$ agregou os indicadores hospitalidade do povo $\left(\mathrm{X}_{8}\right)$ e o aeroporto $\left(\mathrm{X}_{24}\right)$ sendo, pois, nomeado de "Capacidade de recepcionar o turista". A hospitalidade também é um item bastante considerado pelos turistas. Quem se desloca da sua residência espera sempre ser bem recebido, com simpatia e atenção, expectativas principalmente de quem vem para o Nordeste. Isto pode ser percebido pelo turista em um dos meios de chegada mais utilizados em Ilhéus, o aeroporto.

O oitavo fator $\left(\mathrm{F}_{8}\right)$, classificado como "Capacidade em acolher o turista", agregou apenas o indicador meios de hospedagem $\left(\mathrm{X}_{9}\right)$. Ilhéus tem se destacado pela estrutura e serviços disponibilizados de alojamento. No destino, é possível encontrar desde residências para aluguel, pousadas (de diversos estilos e preços) até resorts, isto em todas as áreas do município (Tabela 3).

\section{Conclusão}

O destino Ilhéus apresenta avanços e entraves ao progresso da atividade turística quando avaliadas as condições dos diferentes elementos que compõem a oferta turística do município, na alta estação do ano de 2007. Segundo os turistas, os recursos naturais se destacam porque promoveram grande satisfação, por isto, estão atentos à qualidade ambiental e com o nível de limpeza, principalmente das praias. Embora o carnaval e a capoeira sejam manifestações mais presentes na alta estação, período que os turistas têm acesso a alguns pontos turísticos, o patrimônio histórico-cultural e as manifestações populares não têm atendido às expectativas de quem chega a Ilhéus.

Dos equipamentos e serviços, três itens se destacam como satisfatórios: a hospitalidade do povo, a gastronomia e os meios de hospedagem. Todavia, os abordados não se agradaram com as empresas de receptivo, os guias e as diversões noturnas. Quanto à infra-estrutura, os meios de comunicação atenderam as necessidades da maior parte dos que chegaram a Ilhéus, porém a segurança pública, a limpeza pública, a sinalização urbana e a sinalização turística não agradaram. 
A avaliação da oferta turística do município de Ilhéus, na alta estação do ano de 2007, indica que a satisfação do turista depende não só da capacidade do destino em oferecer atrativos naturais exuberantes, é preciso atentar que o contentamento também depende da preservação e conservação ambiental, da qualidade dos equipamentos, serviços e da infra-estrutura disponível. Dessa forma, espera-se que estas análises auxiliem o planejamento desta atividade de forma que as decisões de investimento sejam acertadas e venha promover consolidação do setor e o desenvolvimento sustentável do município de Ilhéus.

\section{Referências}

ANDERECK, K.; VOGT, C. A. 2000. The relationship between residents' attitudes toward tourist and tourism development options. Journal of Travel Research, v. 39, p. 27-36, Aug.

BENI, M. C. 2003. Análise estrutural do turismo. 2. ed. São Paulo: SENAC.

LAGE, B. H. G.; MILONE, P. C. (Org.). 2000. Turismo: teoria e prática. São Paulo: Atlas.

LIMA, M. C. 2004. Monografia: a engenharia da produção acadêmica. São Paulo: Saraiva.

MALHOTA, N. K. 2001. Pesquisa em marketing: uma orientação aplicada. Porto Alegre: Bookman.

MAROCO, J. 2003. Análise estatística com utilização do SPSS. Lisboa: Edições Silabo.

PAZ, M.; FREITAS, C.; NICOLA, D. 2006. Avaliando a intensidade da modernização da agropecuária gaúcha: uma aplicação de análise fatorial e cluster. In: Congresso Brasileiro de Economia e Sociologia Rural, 44, Fortaleza. Anais... Fortaleza: SOBER, 2006, p. 1-20. (DC-ROM).

ROCHA, A. et al. 2006. Economia baiana: retrospectiva 2006. Bahia Análise \& Dados. Salvador, v. 16, n. 3, p. 373-383, dez.

SETUR - Secretaria de Turismo do Estado da Bahia. s/d. Disponível em: <www.setur.ba.gov.br/ estrategia_turistica.asp>. Acesso em: 28 mar. 2008.

SCHROEDER, T. 1996. The relationship of residents' image of their state as a tourist destination and their support for tourism. Journal of Travel Research, p. 71-73, Spring.

SHARMA, S. 1996. Applied multivariate techniques. New York: John Wiley \& Sons.

KOZAK, M.; RIMMINGTON, M. 2000. Tourism satisfaction with Mallorca, Spain, as an off-season holiday destination. Journal of Travel Research, v. 38, p. 260-269, Feb.

\section{Recebido em: 08/07/2009}

Aprovado em: 05/12/2009 